\title{
Analysis of Successful reason of "Masters in Forbidden City”
}

\author{
Yang Song \\ Baicheng Normal University, School of Literature, Baicheng, Jilin, China, 137000
}

Keywords: TV Documentary; “Masters in Forbidden City”; Success Reasons

\begin{abstract}
The documentary has always been less concerned about the type of film, the content of the edge of the favorite or popular theme, enthusiastic awards and broadcast less, especially in the form of a variety of television entertainment wave, the documentary has been hidden in trouble. In January 2016, China Central Television broadcast a documentary - "Masters in Forbidden City" This is the documentary film of the remains of the ruins of the ruins of the ruins of the ruins of the National Palace Museum, which set off a new cultural craze for the Chinese documentary and opened a new form of "Internet + Documentary". In this paper, "Masters in Forbidden City" as the object of study, from the creative level and the dissemination of its research, analysis of its success reasons, with a view to the growth of Chinese television documentary and enlightenment.
\end{abstract}

\section{Introduction}

With the changes in the social system and documentary filming, the transformation of production consciousness, in recent years, the field of documentary constantly emerging works. Some artistic, ornamental, commercial and other excellent characteristics of the combination of fine documentary as a new model of domestic documentary, has been widely recognized by the community.

As the National Palace Museum 90 anniversary of the documentary and filming, "Masters in Forbidden City" is about the preparation of the Imperial Palace of the repair group of cultural relics repair artifacts story. This is the only documentary to date that shows the restoration of the precious heritage of the Forbidden City. The film in the CCTV record channel for the first time broadcast, and then in the network communication has been widely praised. In the love of the odds of the client more than 6.95 million times the number of hits in the bar code video site beeps the number of times as high as 212 million times the number of times, Douban users is playing a very rare documentary area of 9.4 points, many times to occupy micro-blogging Hot topics and hot search list. Multiple data show that "Masters in Forbidden City" won the majority of the audience's support, has achieved great success.

"Masters in Forbidden City" on the network overnight and received praise, to become with the "tongue on the Chinese" comparable to another successful documentary, it is so much attention, must be a combination of many factors result.

In this paper, "Masters in Forbidden City" in the network popular as the main line, from the creative level, the communication level and its all aspects of the analysis, summed up the reasons for its success, and further elaboration of its success on the domestic documentary inspiration, advice on the development of documentary in our country.

\section{The Analysis of Success Reasons of the "Masters in Forbidden City"}

Creative Level. Elegant and creative ideas. From the large documentary "Forbidden City" "Taipei Palace" to "Palace 100", by virtue of the high-end production equipment before and after the shock of the audio-visual effects and the atmosphere of the atmosphere caused a high degree of concern.

2016 broadcast of "Masters in Forbidden City" with the Palace of the original documentary grand narrative is different, it is through the eyes of modern people and the general public 
awareness of civilians really do a good taste, let the audience resonate.

First of all, the documentary production team has a dark modern and modern vision. "Masters in Forbidden City" crew members are the vast majority of two or three years old young people. Shoot the four months, they work with the National Palace Museum artifacts to work together to get off work, live together. With the young people's observation perspective to lead the audience to appreciate the ancient Palace of the alternative style, abandoned the history of the Forbidden City record the main line, through the modern artifacts repair division work and life records, the first time on the history of Chinese cultural relics finishing, the restoration technology of cultural relics is presented in public. It uses modern methods to reinterpret traditional culture, thus building a bridge between history and today's connections.

Second, the documentary reflects the people-oriented civilians' consciousness. "Masters in Forbidden City" crew breaks through the traditional perspective, with a younger, more way to tell the story of the Forbidden City. Daily on time to get off work, bored tease cat, fruit mature when taking time to make an apricot, no overtime. The Forbidden City is closed on Mondays and can be enjoyed by the restorers alone on the open plaza. Skilled craftsmen are also close to the masses of ordinary people, they are exposed every day a variety of treasures, and occasionally take the ancient repair painting and calligraphy people joke will be strict to watch the perfect operation. This approachable work and life can hit the audience's heart, attracting the audience's attention. Cultural relics repair experts as individual characters in the narrative is a people-oriented civic awareness of the important embodiment.

The ingenious creative content. Three episodes of the documentary production of another way, through the history and architecture of the Forbidden City records the red walls of the palace weaving embroidery, palace watches and clocks, ceramics, paintings, bronze, treasure inlay, wood, lacquerware and other categories of cultural relics repair story and repair division of life, leading the audience to open a unique trip to the Forbidden City. The first time the use of close-up will be the cultural relics repair workers superb skills and work scenes in front of the public debut; the first time the top cultural relics repair process and the daily life of workers interspersed reproduction; the first through the field of cultural relics repair show traditional craft of the inheritance, faith and change, showing the big country craftsmen choose a thing, the ultimate life of professionalism.

Artifact restoration division is a class of workers we do not know, in the audience and they are mysterious enough to attract people's attention. Although the process of restoration of cultural relics has not been more comprehensive and more detailed description, but in this 150 minutes, but let the audience a taste of the great artisans of the style, although they have superb skills, but calm and kind, indifferent leisurely, warm full. Such as watches and clocks to repair the master Wang Jin watch their watch has been repaired, the eyes with tears, feeling that Smart watches cannot be seen for the world, their career before the end do not know cannot repair more watches and clocks; Lacquerware repair group of workers to overcome the difficulties of allergies to paint, all day to endure pungent paint taste. Forbidden City repair skills still follow the traditional mentoring system heritage, repair division has the spirit of hard work is the modern people to find and lack of spirit.

Subtle creation techniques. "Masters in Forbidden City" is used close to the documentary with the film, live at the same time and real reproduction of the shooting method. In order to be able to more intuitive and stereoscopic display of cultural relics repair skills, documentary in the shooting lacquer group master repair musical instruments and Qianlong royalties and other cultural relics at the same time, but also with Min Junrong to participate in and record the night to the outskirts of the collection of tree lacquer events. In the process of displaying the master of Wang Wu Sheng repair Tang three color horses but also shot in order to maximize the reproduction of three-color horse posture, read the information, observe the contemporary works, and other repair group master to discuss the process of research. The third episode of painting and calligraphy repair process, the repair group of young repair division will be repaired painting and calligraphy samples carefully sorting and collection, so as not to extract in the future. Cultural workers are fine and rigorous work attitude, more able to impress people. Careful reproduction of the workers is on the restoration of cultural relics seriously, so that more people know the cumbersome work, and better improve the 
documentary narrative ability and expressive force.

"Masters in Forbidden City" Although the length is very short, but the structure of refining clear, according to the various types of repair division, each episode about several different categories of repair. The film is mainly interception of cultural relics in the process of representative events interspersed narrative, and there are obvious differences between the plains, but also to ensure that the continuity of the story is not destroyed. At the same time, the film shows the fun of cultural relics in the process of repair, it is easy to resonate with the audience. Such as painting and calligraphy group repair division work leisure time, sitting on the side holding the guitar side playing side singing. Another example is the repair division in the studio outside the small garden children planted garden, feeding the cat to eat birds. These interesting and refined plots make the film more in line with the taste of modern audiences.

The Communication Level. A wide range of transmission. First of all, through the traditional television transmission, "Masters in Forbidden City" to improve the visibility, and had a certain impact. From January 7, 2016, “Masters in Forbidden City” in CCTV9 daily broadcast a set, a total of three days. China Central Television because of its unique geographical advantages and state support, in the dissemination of mainstream culture and the elite of the authority of the high. Although the "Masters in Forbidden City" after the broadcast did not get the sensation in the audience, but the authority of the television record channel to a certain extent for the documentary reputation to provide a prerequisite for its network spread basis. Secondly, through the "Masters in Forbidden City" in a variety of network platform to spread the spread of wider range, increased audience recognition, improve the impact of documentary.

"20:20 at 20:30 on January 20, micro-blogging big V" @ M king called me to patrol "made micro-blogging on the "Masters in Forbidden City" praised, and in the text attached to the documentary below the play The future of other large V have been forwarded, "People's Daily" "China Youth Daily" and other authoritative media official micro-blogging also helped me in the Imperial Palace repair artifacts quickly boarded the micro-blogging hot topic list. "

With the increasing popularity of Internet users, barrage sites began to rise in China and popular. Barrage website refers to the real-time barrage to send the main characteristics of the video site, its unique barrage so that these sites from the beginning of the birth of much attention, and one of the leaders is the site beep, also known as B station. Different from the traditional video broadcast site, barrage website in the playback of images, video, but also joined the real-time commentary, and to cover the text-based video images supplemented by the form of presentation. B station broadcast "Masters in Forbidden City", after 90, 00 young people began to warmly sought after, just a few days, click on the record high. "Now young people are reluctant to learn tapestry so tedious skills", the screen immediately "I would like to ah!" "I learn xx, I do not?" Filled. Ji Dongge in the empty Palace Square, riding a ride, the barrage appeared "so bad Oh!" "I want to ride in the Imperial Palace," the words.

Barracks in the endless stream of words played the role of the network of opinion leaders, so that "Masters in Forbidden City" in the network platform fame. The audience plays the role of the communicator, shares the quality information with the surrounding community, and thus weaves a propagating magnetic field. The diversified network communication model has made outstanding contributions to the success of the relics in the Forbidden City, which not only increased the way the audience watched, expanded the field of communication, but also strengthened the audience's recognition of the documentary.

The younger object of communication. Barnival video site users, 90 after the young groups accounted for 75 percent, of which 00 after more than 30 percent of users. This is a young group with a personality and they have a strong curiosity, and can be flexible to master all kinds of social networks.

Now, 90 generations are accustomed to not watch TV. "90 after the media use of the study report" shows: most of the 90 after a day to watch TV less than half an hour, of which $20 \%$ of 90 does not touch the TV. "Cenozoic Internet users study" shows: the phone to see the video after 95\% of more than 90 percent However, although the audience view of the game has changed, but the 
audience on the film quality requirements did not decrease. Today, 90, 00 after the young people began to contact the Internet from an early age, entertainment, diversification of low-quality information gradually resentment. With the increase of knowledge and the perfection of values, we began to pay attention to the film with profound cultural connotation. "Masters in Forbidden City" this carry forward the traditional culture, advocate craftsmen spirit of the documentary, and the chaotic entertainment culture is different, so much loved by young people. In the film "rejuvenation" and other idioms appear and there will be barrage flying: "good culture!" There are many viewers on the barrage to send want to go to the Forbidden City to study cultural relics repair. From these barrages can be seen, "Masters in Forbidden City" to convey the traditional charm and craftsmen spirit, to meet the audience a higher level of demand, no longer just for recreation and entertainment, and began to enrich the spirit of the world in entertainment.

\section{The Inspiration of “Masters in Forbidden City" on the Domestic Documentary}

Use New Perspective to Show the Human Spirit. "Masters in Forbidden City" to make their own creation and exploration of many new ideas, one of the most prominent point is that by the depths of the little remnants of the ruins of the story of cultural relics to show the traditional Chinese humanistic spirit. The craftsmen in the field of decades of work attitude, clear sky, gentle and humble life quality of the show, so that the traditional Chinese excellence, the courage to study the spirit of dedication to the perfect interpretation of craftsmen. This is the modern fast-paced wave of people generally yearning and pursuit of life. Compared with the same outstanding television documentary can be found at the present stage of the audience favorite documentary topics based on today's most common social reality in China, and a new perspective, new forms to show the theme. For example, in recent years, the favorite "Chinese on the tip of the tongue" is based on the humanities perspective, selected the daily life of the most concerned about the diet theme, not only the food around China attractive and delicious, but also show the magic of nature and Chinese life story. A Road delicious witnessed the changes in personnel, craft heritage, warmth moment. Another example of "tea, a leaf of the story" tells the story of tea culture around the world, of which more than 60 countries in different countries, "tea" and the story of tea to lead the audience to experience the power of tea affected the world. Six episodes of the film, each set of keywords are with a strong human color, such as "the temperature of the land and palm" "a bowl of tea to see people" and so on.

Develop Civilians Narrative Space. "Masters in Forbidden City" a prominent feature is to love moving people, cultural relics repair work and warmth of the story of integration, both to the mystery of cultural relics repair, but also from the daily work of the repair division to show close to the people's perspective. This feature is the past documentary civilians of the "narrative space" aspects of the transcendence and perfection.

The last century of the Chinese documentary works about the story part of the less, and there is no prominent from the transfer, each part is to create a whole image and service. And "Masters in Forbidden City" in the form of more similar to his right to listen to the story, each narrative group, different scenes and sub-lens have a more closely related relationship between the narrative story of the splicing and rhythm fast. Closely around a theme and narrative, set a number of clues to lead the audience gradually close to the content of the film to express the truth. The narrative style of this documentary shows the characteristics of civilians, more easily accepted by ordinary audiences and recognition. Such as "look at the Great Wall" "kindergarten" "Longji" and a number of outstanding documentary also in the narrative way to go civilians line. The creation of documentary in our country should be more development of this narrative way, and constantly to the documentary from small minority communication into the direction of mass communication efforts, so that documentary writing to a greater extent to meet the emotional needs of ordinary viewers. Better to improve the construction of "narrative space".

Integrate New Communication Model. 2016 documentary get a lot of gains in the transition. "Internet + documentary" became the sunny model. Coupled with the support given by the relevant policies, many video sites have been handed the documentary on the home page. The documentary 
plays more than 5 billion times on the site. The video website provides a high-quality platform for the dissemination of documentaries.

"Masters in Forbidden City", for example, the strong spread of new media to make it in the traditional television broadcast and not too much attention to the case, but in the barrage site overnight burst red. The network in this process shows a strong communication utility. Therefore, the pursuit of better development of documentary process in the integration of new communication model is imperative.

However, the "Internet + documentary" model requires the documentary pre-production must adapt to the Internet characteristics, so that the film has a rhythm, the overall short, easy to understand and so on, so as to meet the viewing habits of network users, rather than only the Internet as a platform to play use.

Establish Commercial Operation Mode. From the production and launch aspects of contrast, we can find that the Chinese documentary and foreign documentary in the market and commercial operation has a very clear gap. Although the documentary film as the representative of the CCTV documentary works in the channelization, internationalization and many other aspects of the attempt, creative ideas and methods have a greater innovation, the quality of the documentary has also been greatly improved. But have to admit that the domestic documentary market channels have not yet opened up a successful, slightly single sales model, documentary deep-seated business value did not get better mining, market-oriented road long way to go. The leader of the commercialization of documentary films was the BBC of the British Broadcasting Corporation, and many of its documentaries were of great concern worldwide. Such as "the pulse of the earth" "life" and other natural documentary, as well as in recent years launched the "Chinese New Year" such a human documentary. BBC from the film production to the global distribution has formed a mature mode of operation. With excellent documentary quality as the support, the new media market expansion and a variety of broadcast channels for the conditions, large-scale professional awards for the driving force, to achieve the spread of the effect can be seen. "Chinese New Year" earned a lot of praise of the Chinese people, word of mouth bursting. "Earth pulse" is winning numerous, known as "God", once launched was regarded as a classic.

At the present stage, the degree of globalization of trade and trade is getting higher and higher. The Chinese documentary should not only be used as a record and reflect the reality. Only by means of simple digital statistics and awards such as ratings and click rate can prove its own value. A best-selling commodity that maximizes the business interests as an important issue for all producers to think about at this stage. Similar to the standard of commercial cinematography, it is difficult to form a wide range of influence and demonstrative effects on a documentary that is recognized by the audience but cannot be marketed.

\section{Conclusion}

Domestic documentary is ushering in the "spring", documentary farewell past boring old-fashioned statement, is a lively form to reproduce the vitality. "Masters in Forbidden City" as a 90th anniversary for the National Palace Museum and the introduction of the documentary, elegant and popular creative ideas, ingenious creative content, meticulous creative techniques and a wide range of means of communication makes the " This simple documentary can be meteoric rise. In this era of information transients, social progress and the needs of the audience require documentary workers to continuously improve the level, with the pace of the times. Chinese documentary's commercial transformation of the road long way to go, hope that "Masters in Forbidden City" can be used as a success story in the transition period of documentary film for the development of documentary to bring innovation and inspiration.

\section{References}

[1] Wang Zili. "Vegetable sister" network popular interpretation of the spread [J]. News knowledge, $2014(6)$ 
[2] Yanjing. Documentary "Masters in Forbidden City" success factors [J]. Sound of the world, 2016 (8)

[3] Liu Mengzhi. From the grand narrative to the micro-narrative - the documentary "I in the Imperial Palace repair cultural relics," the creative concept of innovation[J]. Modern communication, 2016 (9)

[4] Wang Wan Ni. Small incision to reveal the role of the big theme in the grand narrative documentary - "Masters in Forbidden City" as an example[J]. Modern audio-visual, 2016 (12)

[5] Du poetry painting. "I am in the Imperial Palace repair cultural relics" network popular communication analysis[J]. News world, 2016 (11) 